\title{
Carpal tunnel surgery: patient preferences and predictors for satisfaction
}

This article was published in the following Dove Press journal:

Patient Preference and Adherence

26 September 2012

Number of times this article has been viewed

\section{Grant D Shifflett \\ Christopher J Dy \\ Aaron Daluiski}

Department of Orthopaedic Surgery, Division of Hand and Upper Extremity Surgery, Hospital for Special Surgery, New York, NY, USA
Correspondence: Aaron Daluiski Department of Orthopaedic Surgery, Division of Hand and Upper Extremity Surgery, Hospital for Special Surgery 523 E 72nd St, New York. NY 10021 , USA

$\mathrm{Tel}+\mathrm{I} 2126061284$

Fax +I 2122888260

Email daluiskia@hss.edu
Abstract: Carpal tunnel syndrome is a debilitating disease of the upper extremity affecting patient function and quality of life. Surgical interventions have been developed that effectively treat this disease. However, there remains a subset of patients who are not fully satisfied with their outcome. Extensive investigation has been undertaken to analyze preoperative factors predictive of higher patient satisfaction. This review summarizes the role of unique patient characteristics and patient psychology, worker's compensation, patient demographics, certain clinical features, and patient preferences and expectations regarding patient satisfaction following carpal tunnel surgery. Understanding the complex nature of patient satisfaction will enable surgeons to indicate patients for surgical intervention better, provide appropriate preoperative counseling, and manage expectations postoperatively.

Keywords: outcome, workers' compensation, biopsychosocial, patient demographics

\section{Introduction}

The incidence of carpal tunnel syndrome is 3.5 cases per 1000 person-years, making it the most common compressive neuropathy of the upper extremity. ${ }^{1}$ Carpal tunnel syndrome affects the median nerve distribution, producing a constellation of symptoms that includes numbness, tingling, and pain, as well as functional deficits that include muscular atrophy and weakness. Carpal tunnel surgery (with release of the entrapped median nerve) is an effective treatment for patients with carpal tunnel syndrome recalcitrant to conservative measures. Open and endoscopic methods achieve good or excellent outcomes in approximately $70 \%-90 \%$ of patients. ${ }^{2}$ A tremendous amount of research has been dedicated to identifying clinical variables that may predict the success and failure of surgical treatment.

While patient satisfaction is a critical component in determining success following carpal tunnel surgery, it remains poorly understood. An effective evaluation of patient satisfaction should extend beyond the variables traditionally included in the surgical literature, and should explore the psychosocial aspects of the patient and their decision-making process; demographic contributions such as age, gender, and workers' compensation; and patient expectations and desired outcomes following the surgical outcome.

Preoperative discussion about patient expectations allows the surgeon to counsel the patient on appropriate postoperative expectations, while also giving the surgeon a framework to best judge success in each patient. Many factors influence patient satisfaction, and each patient has an individual set of priorities that contribute to their ultimate level of satisfaction. 


\section{The patient and patient psychology}

Each patient has a very personal understanding of the disease process, view of the physician-patient relationship, and level of confidence in the available treatment options. The biopsychosocial model of health care attempts to reconcile the traditional decision-making strategies of medicine with the subjective, individualized outlook of each patient. ${ }^{3}$ Outcomes research in carpal tunnel surgery has highlighted the complex nature of predicting and obtaining successful outcomes ${ }^{4}$ and application of the biopsychosocial model may be beneficial by improving outcomes.

Patients are taking an increasingly active role in their health care and decision making. The wide availability of medical information through the Internet and other sources has led to a more informed patient base that may have a greater understanding of the risks, benefits, and outcomes of surgery. ${ }^{5-8}$ Traditionally, three fundamental approaches to clinical decision-making have been emphasized: paternalistic, shared, and consumerist. ${ }^{9}$ The evolution of patient-centered care has moved decision making from the paternalistic approach towards a more shared or consumerist approach. Gong et al demonstrated that over three-quarters of patients with carpal tunnel syndrome preferred to share decision making with their physicians. ${ }^{10}$ Moreover, recent literature has shown greater patient satisfaction when shared decision making is employed. ${ }^{11}$ Establishing a relationship with patients and involving them in the decision-making process can help increase patient satisfaction.

Understanding and adapting to patient psychology is an essential aspect of the doctor-patient relationship. An individual psychological response accompanies every illness and influences the way the patient perceives and responds to the diagnosis. For example, a patient's mental status may affect the severity of symptoms, both pre- and postoperatively, and may lower his or her satisfaction after surgical intervention. ${ }^{12}$ Several factors may contribute to this finding, including delayed presentation for care, inability to comply with postoperative instructions, and a wholly pessimistic outlook. More specifically, depression has been associated with dissatisfaction. ${ }^{13}$ While poor coping skills could inherently undermine a patient's response to the treatment of any medical condition, this has been specifically investigated following carpal tunnel release. ${ }^{14}$

Perceived disability is also important to understanding patient satisfaction. Kelley-Moore et al defines perceived disability as "a patient's subjective assessment of their own health and functional status." ${ }^{15}$ Perceived disability is highly individualized and depends on how a patient internalizes feedback from loved ones and physicians, the availability of emotional and physical support a patient encounters in times of major need, and the ability of the patient to fulfill certain social roles. ${ }^{16}$ Ultimately, the way a patient views his or her level of disability has a profound effect on his or her expectations of and response to treatment.

Treatment strategies that incorporate the biopsychosocial model acknowledge the characteristics inherent to the patient. These strategies consider the patient's view of the disease process; the stability of his or her mental state regarding understanding the risks, benefits, and expectations of surgery; and ultimately, the patient's postoperative ability to cope with postsurgical pain, hand therapy, and overall outcome.

\section{Workers' compensation}

Over $10 \%$ of orthopedic services in the United States are paid for by workers' compensation. ${ }^{17}$ Injuries to the upper extremity are the most common type of all workplace-associated injuries, with carpal tunnel representing approximately $3 \%$ of cases and requiring a median of 27 days off from work. ${ }^{17}$ The association between workers' compensation and treatment outcomes in carpal tunnel syndrome is complex. Workers' compensation claimants utilize a greater share of the available surgical and physiotherapy treatments, ${ }^{18}$ yet data suggest that they fare worse than patients without third-party compensation incentives. ${ }^{18}$ Indeed, workers' compensation claims have been linked to more severe symptoms, decreased satisfaction, prolonged long-term disability, and worse objective outcomes. ${ }^{12,19}$ For example, workers with an attorney involved in their cases described more severe symptoms and lower satisfaction with treatment when compared to patients with no attorney involved in their cases. ${ }^{19}$ Fewer patients with workers' compensation claims return to their previous jobs, with a majority attributing their inability to work to symptoms of carpal tunnel syndrome. ${ }^{20}$ Workers' compensation patients generate a higher physician workload, and therefore a higher cost of health care, in the form of more-frequent office visits, documentation, and phone calls, and the performance of more diagnostic studies. ${ }^{21}$ Overall, patient satisfaction appears to be lower in this subset of patients. ${ }^{22}$

The concept of moral hazard refers to the change that occurs in a patient's behavior when that individual is no longer responsible for the costs of his or her actions. ${ }^{23}$ Day et al describe moral hazard as "a change in a person's behavior when that individual no longer bears the cost of his or her actions. ${ }^{.23}$ This concept has been explored in relation to workers' compensation claims as a possible explanation for poor outcomes. ${ }^{23,24}$ Workers' compensation benefits vary 
by state, but typically involve health care cost coverage, paid medical leave from work, and other employee financial benefits. When patients have an outside agency playing such a large role in their care, it is argued that patients are encouraged to be in, and remain in, the sick role. ${ }^{23}$ Multiple references in the literature highlight the fact that as workers' compensation benefits become more generous, the frequency and severity of claims increase. ${ }^{25-28}$ Furthermore, one study found that a $10 \%$ increase in workers' compensation benefits led to an up to $11 \%$ increase in the number of workers' compensation claims. ${ }^{29}$ These phenomena may be partially explained by moral hazard as patients are offered incentives to utilize a greater share of the health care system. This becomes particularly important in diagnoses that are heavily reliant on subjective data from patients, such as those with carpal tunnel syndrome. This clearly represents a barrier for the surgeon in interpreting a patient's severity of disease, response to treatment, and long-term prognosis.

Another hypothesis to explain poor outcomes in workers' compensation patients is secondary gain. ${ }^{30,31}$ Secondary gain is defined as the benefit obtained indirectly from organic or professed illness. ${ }^{32}$ Strong consideration must be given to secondary gain, especially in clinical studies that rely on subjective patient-rated questionnaires as determinants of outcome. This may be explained by the potential reporting bias generated by ulterior motives. However, it should also be noted that the effect of workers' compensation must be viewed within the context of the relevant health care system. Patient preferences and decisions may differ, for example, in a heavily privatized system (such as in the United States) compared to a single-payer system. The implications of workers' compensation cases and medical-legal disputes over a physician's management of a patient cannot be overlooked. Pressure from attorneys may drive physicians to more aggressively utilize resources to avoid unnecessary scrutiny and possible litigation. The physician should be aware of these inherent biases while striving to provide the best care for patients with carpal tunnel syndrome.

\section{Patient demographics}

Like many other procedures, outcomes after carpal tunnel surgery can be influenced by age, gender, race, socioeconomic status, and education level. ${ }^{33-36}$ Previous investigations have not yielded a consensus on the effects of age or gender on satisfaction after carpal tunnel surgery. However, a recent investigation with long-term follow-up has shown substantial satisfaction after carpal tunnel release in elderly patients, with a satisfaction rate of $85 \%$ at the 5 -year follow-up. ${ }^{37}$ Moreover,
Ettema et al compared nonoperative to surgical treatment of carpal tunnel syndrome in patients over 70 years of age and showed increased satisfaction after surgical management. ${ }^{36}$ The appropriate approach to the elderly patient, therefore, may be similar to that for younger patients: identify and indicate the appropriate surgical candidates.

Gender-based disparities in outcomes are becoming increasingly apparent within the field of orthopedic surgery. ${ }^{38}$ While patient gender has been accounted for in most studies regarding carpal tunnel surgery, these studies have not demonstrated any substantial influence of gender on outcomes after carpal tunnel surgery. ${ }^{13,19,34}$ However, Hansen and Larsen demonstrated that women have higher satisfaction than men after carpal tunnel surgery. ${ }^{39}$ While there is no clear consensus on the influence of gender on outcomes after carpal tunnel treatment, gender-based differences in a patient's general outlook on disease and expectations for treatment may exist, and further investigation is warranted.

\section{Clinical features predictive of higher satisfaction}

An understanding of the effect of the disease process on quality of life is helpful in guiding treatment choices. Patient satisfaction is rooted in the physician's ability to understand the patient's functional impairment and to tailor treatment appropriately. ${ }^{37}$ When evaluating the patient with carpal tunnel syndrome, the physician should identify factors that have previously been associated with poorer outcomes. Turner reviewed the literature over the past 20 years for predictors of poor outcome and found that patients with diabetes mellitus, thoracic outlet syndrome, double-crush phenomena (where a peripheral nerve is compressed in two separate locations), a history of alcohol abuse, and a history of tobacco use have a worse prognosis. ${ }^{40}$ Furthermore, worse outcomes were also observed in patients with normal preoperative nerve conduction studies, in those with signs of abductor pollicis brevis muscle wasting, and in workers' compensation cases involving preoperative litigation. ${ }^{40}$

Predictors for higher satisfaction after carpal tunnel treatment can also be solicited from clinical evaluation. Gong et al found that clinical predictors of higher satisfaction were nocturnal pain and the absence of cold intolerance. ${ }^{41} \mathrm{In}$ addition, patients who were not experiencing any subjective weakness had high rates of satisfaction. In general, patients with symptoms indicative of early carpal tunnel syndrome without resultant muscle weakness have greater satisfaction and more predictable outcomes from their surgery. Once median nerve compression has progressed to clinically 
evident muscle atrophy (in carpal tunnel syndrome), the goal of carpal tunnel release is to halt the further progression of disease. In these cases, patient satisfaction is more difficult to predict and may be related to the patient's return to a premorbid level of muscle function.

\section{Patient preferences for outcomes, expectations, and satisfaction}

Increasing attention is being given to patient preferences and expectations throughout the musculoskeletal literature. As discussed previously, patients with carpal tunnel syndrome often complain of a combination of numbness, night pain, pain, functional limitation, or weakness. Detailed evaluation of patients who undergo surgery reveals differences in their prevailing symptoms and preferences. Bessette et al found that the most important reason for choosing surgery was night pain and numbness in nearly $60 \%$ of patients; however, $17 \%$ chose functional improvement. ${ }^{12}$ Night pain and numbness are symptoms that quickly and reliably improve with surgery, whereas functional improvement is less predictable and can take much longer. Despite these considerations, preference for grip strength was the only statistically significant variable associated with satisfaction; specifically, preference for grip strength was associated with lower satisfaction. Kadzielski et al also looked at preoperative expectations and found no significant correlation with patient satisfaction. ${ }^{42}$ After multivariable analysis, Kadzielski et al found that simply the fulfillment of expectations explained most of the variance in postoperative satisfaction.

The individual context of each patient's expectations and preferences is important to understanding their influence on outcomes. As discussed previously, the patient's mental health status and coping skills may influence the patient's overall perception of the disease process, perceived disability, and subsequent treatment outcomes. Workers' compensation status and education level are intimately linked with an expressed interest in returning to work. Certainly, the health care system in which a patient receives care may result in unique differences in expectations and levels of satisfaction. One aspect of patient expectations not considered in the current literature is the nature and extent of the discussion that the surgeon has with each patient prior to surgery. Not all surgeons present treatment options in a similar fashion, and each patient may respond differently to a given preoperative discussion. There is a clear need for a preoperative questionnaire or survey for evaluating and measuring patients' preoperative expectations and postoperative fulfillment.
It is important for physicians not only to understand the patient's perceptions, but also to delve deeper to understand the patient's rationale for their views. Patients may have an uninformed or distorted view of the risks, benefits, and potential complications of surgery. Both under- and overemphasizing the perceived risks is common, but patients are particularly prone to misconstrue negative outcomes. ${ }^{43}$ Developing a rapport with each patient and understanding his or her fears, concerns, and perception of treatment options cannot be overstated, and if done properly, can optimize the patient's satisfaction with treatment.

\section{Conclusion}

In the appropriately selected patient, carpal tunnel surgery has the potential for excellent outcomes with high levels of patient satisfaction. In a certain subset of patients, however, a reliable outcome cannot be predicted. Many variables have been studied to explain this, including baseline mental health status, workers' compensation, certain demographic data, and patient expectations. Despite extensive investigation, there remains an incomplete understanding of this information, and further study is warranted.

Patient-reported measures of health status are crucial to the evaluation, indication, treatment, and ultimate outcome of carpal tunnel surgery. ${ }^{19}$ The evolution of care for patients with carpal tunnel syndrome must involve a closer examination of the patient that extends beyond surgical treatment of the disease. Physicians should work to accurately identify patients who are at greatest risk for poor outcomes and use preoperative education and counseling to establish appropriate, customized expectations for treatment. An evaluation of patients through an individualized, patient-centered approach will enable the most complete assessment and treatment of patients with carpal tunnel syndrome.

\section{Disclosure}

The authors report no conflicts of interest in this work.

\section{References}

1. Nordstrom DL, DeStefano F, Vierkant RA, Layde PM. Incidence of diagnosed carpal tunnel syndrome in a general population. Epidemiology. 1998;9(3):342-345.

2. Brown RA, Gelberman RH, Seiler JG 3rd, et al. Carpal tunnel release. A prospective, randomized assessment of open and endoscopic methods. J Bone Joint Surg Am. 1993;75(9):1265-1275.

3. Katon W, Kleinman A. A biopsychosocial approach to surgical evaluation and outcome. West J Med. 1980;133(1):9-14.

4. Vranceanu AM, Ring D. Factors associated with patient satisfaction. J Hand Surg Am. 2011;36(9):1504-1508. 
5. US Department of Commerce. A Nation Online: How Americans Are Expanding Their Use of the Internet [survey based on Sep 2002 census data]. Feb 2002. http://www.ntia.doc.gov/legacy/ntiahome/dn/html/ anationonline2.htm. Accessed June 19, 2002.

6. FIND/SVP American Internet user survey, May 1997 (New York: FIND/SVP Inc, 1997). http://www.dovepress.com/author_guidelines. php?folder_id $=208$.

7. Gingrich N. Health Information Infrastructure, 1996 Keynote Address. Washington, DC, USA. Apr 1996.

8. Shortliffe EH, editor. Networking Health: Prescriptions for the Internet. Washington, DC: National Academy Press; 2001.

9. Charles C, Gafni A, Whelan T. Decision-making in the physician-patient encounter: revisiting the shared treatment decision-making model. Soc Sci Med. 1999;49(5):651-661.

10. Gong HS, Huh JK, Lee JH, Kim MB, Chung MS, Baek GH. Patients' preferred and retrospectively perceived levels of involvement during decision-making regarding carpal tunnel release. J Bone Joint Surg Am. 2011;93(16):1527-1533

11. Golin C, DiMatteo MR, Duan N, Leake B, Gelberg L. Impoverished diabetic patients whose doctors facilitate their participation in medical decision making are more satisfied with their care. J Gen Intern Med. 2002;17(11):857-866.

12. Bessette L, Keller RB, Liang MH, Simmons BP, Fossel AH, Katz JN. Patients' preferences and their relationship with satisfaction following carpal tunnel release. J Hand Surg Am. 1997;22(4):613-620.

13. Lozano Calderon SA, Paiva A, Ring D. Patient satisfaction after open carpal tunnel release correlates with depression. J Hand Surg Am. 2008; 33(3):303-307.

14. Vranceanu AM, Jupiter JB, Mudgal CS, Ring D. Predictors of pain intensity and disability after minor hand surgery. $J$ Hand Surg Am. 2010;35(6):956-960.

15. Kelley-Moore JA, Schumacher JG, Kahana E, Kahana B. When do older adults become "disabled"? Social and health antecedents of perceived disability in a panel study of the oldest old. $J$ Health Soc Behav. 2006;47(2):126-141.

16. Borawski EA, Kinney JM, Kahana E. The meaning of older adults' health appraisals: congruence with health status and determinant of mortality. J Gerontol B Psychol Sci Soc Sci. 1996;51(3):S157-S170.

17. Survey of occupational injuries and illnesses. Counts, rates, and characteristics, 2007. Bureau of Labor Statistics, US Department of Labor. Washington, DC, USA. 2008.

18. Sperka P, Cherry N, Burnham R, Beach J. Impact of compensation on work outcome of carpal tunnel syndrome. Occup Med (Lond). 2008; 58(7):490-495.

19. Katz JN, Losina E, Amick BC 3rd, Fossel AH, Bessette L, Keller RB. Predictors of outcomes of carpal tunnel release. Arthritis Rheum. 2001; 44(5):1184-1193.

20. Higgs PE, Edwards D, Martin DS, Weeks PM. Carpal tunnel surgery outcomes in workers: effect of workers' compensation status. $J$ Hand Surg Am. 1995;20(3):354-360.

21. Kasdan ML, Vender MI, Lewis K, Stallings SP, Melhorn JM. Carpal tunnel syndrome. Effects of litigation on utilization of health care and physician workload. J Ky Med Assoc. 1996;94(7):287-290.

22. Duncan SF, Calandruccio JH, Merritt MV, Crockarell JR, Kakinoki R. A comparison of workers' compensation patients and nonworkers' compensation patients undergoing endoscopic carpal tunnel release. Hand Surg. 2010;15(2):75-80.

Patient Preference and Adherence

\section{Publish your work in this journal}

Patient Preference and Adherence is an international, peer-reviewed, open access journal focusing on the growing importance of patient preference and adherence throughout the therapeutic continuum. Patient satisfaction, acceptability, quality of life, compliance, persistence and their role in developing new therapeutic modalities and compounds to
23. Day CS, Alexander M, Lal S, et al. Effects of workers' compensation on the diagnosis and surgical treatment of patients with hand and wrist disorders. J Bone Joint Surg Am. 2010;92(13):2294-2299.

24. Butler RJ, Hartwig RP, Gardner H. HMOs, moral hazard and cost shifting in workers' compensation. J Health Econ. 1997;16(2):191-206.

25. Worrall JD, AD. The wage replacement rate and benefit utilization in worker's compensation insurance. J Risk Ins. 1982;49:361-371.

26. Butler RJ. Economic determinants of workers' compensation trends. J Risk Ins. 1994;61:383-401.

27. Butler RJ, Worrall JD. Claims reporting and risk bearing moral hazard in workers' compensation. J Risk Ins. 1991;58:191-204.

28. Johnson WG, Ondrich J. The duration of post-injury absences from work. Rev Econ Statist. 1990;72:578-586.

29. Loeser JD, Henderlite SE, Conrad DA. Incentive effects of workers' compensation benefits: a literature synthesis. Med Care Res Rev. 1995; 52(1):34-59.

30. Viola RW, Boatright KC, Smith KL, Sidles JA, Matsen FA 3rd. Do shoulder patients insured by workers' compensation present with worse self-assessed function and health status? J Shoulder Elbow Surg. 2000; 9(5):368-372.

31. Himmelstein JS, Feuerstein M, Stanek EJ 3rd, et al. Work-related upper-extremity disorders and work disability: clinical and psychosocial presentation. J Occup Environ Med. 1995;37(11):1278-1286.

32. Davidhizar R. The pursuit of illness for secondary gain. Health Care Superv. 1994;13(1):10-15.

33. Atroshi I, Johnsson R, Ornstein E. Patient satisfaction and return to work after endoscopic carpal tunnel surgery. J Hand Surg Am. 1998; 23(1):58-65.

34. Hobby JL, Venkatesh R, Motkur P. The effect of age and gender upon symptoms and surgical outcomes in carpal tunnel syndrome. $J$ Hand Surg Br. 2005;30(6):599-604.

35. Marks M, Herren DB, Vliet Vlieland TP, Simmen BR, Angst F, Goldhahn J. Determinants of patient satisfaction after orthopedic interventions to the hand: a review of the literature. J Hand Ther. 2011; 24(4):303-312. e10.

36. Ettema AM, Amadio PC, Cha SS, Harrington JR, Harris AM, Offord KP. Surgery versus conservative therapy in carpal tunnel syndrome in people aged 70 years and older. Plast Reconstr Surg. 2006;118(4):947-958; discussion 959-960.

37. Weber RA, DeSalvo DJ, Rude MJ. Five-year follow-up of carpal tunnel release in patients over age 65. J Hand Surg Am. 2010;35(2):207-211.

38. Dy CJ, Lamont LE, Ton QV, Lane JM. Sex and gender considerations in male patients with osteoporosis. Clin Orthop Relat Res. 2011;469(7):1906-1912.

39. Hansen TB, Larsen K. Age is an important predictor of short-term outcome in endoscopic carpal tunnel release. J Hand Surg Euro Vol. 2009;34(5):660-664.

40. Turner A, Kimble F, Gulyas K, Ball J. Can the outcome of open carpal tunnel release be predicted? A review of the literature. ANZ J Surg. 2010;80(1-2):50-54.

41. Gong HS, Oh JH, Bin SW, Kim WS, Chung MS, Baek GH. Clinical features influencing the patient-based outcome after carpal tunnel release. J Hand Surg Am. 2008;33(9):1512-1517.

42. Kadzielski J, Malhotra LR, Zurakowski D, Lee SG, Jupiter JB, Ring D. Evaluation of preoperative expectations and patient satisfaction after carpal tunnel release. J Hand Surg Am. 2008;33(10):1783-1788.

43. Kassirer JP. Incorporating patients' preferences into medical decisions N Engl J Med. 1994;330(26):1895-1896.

\section{Dovepress}

optimize clinical outcomes for existing disease states are major areas of interest. This journal has been accepted for indexing on PubMed Central. The manuscript management system is completely online and includes a very quick and fair peer-review system. Visit http://www.dovepress.com/ testimonials.php to read real quotes from published authors. 